\title{
Condições Sanitárias e de Saúde em Caiana dos Crioulos, uma Comunidade Quilombola do Estado da Paraíba
}

\section{Sanitary and Health Conditions at Caiana dos Crioulos, a Quilombo Community in the State of Paraíba}

\author{
José Antonio Novaes da Silva \\ Professor Adjunto II do Departamento de Biologia Molecular, Cen- \\ tro de Ciências Exatas e da Natureza da Universidade Federal da \\ Paraíba (UFPB). \\ Endereço: Rua Padre Ayres, 330, Miramar, cep 58043-260, João \\ Pessoa, PB, Brasil. \\ E-mail: barutyळgmail.com
}

\section{Resumo}

Objetivou-se neste trabalho apresentar as condições sanitárias e de saúde humana em Caiana dos Crioulos, reconhecida pela Fundação Cultural Palmares como uma comunidade remanescente de quilombos, em maio de 2005, e efetuar um levantamento sobre o nível de conhecimento de algumas doenças prevalentes na população negra, bem como discutir a utilização da variável "raça" na pesquisa em saúde. A comunidade apresenta uma população de aproximadamente 522 pessoas, majoritariamente crianças e adolescentes, cuja grande maioria apresenta ancestralidade africana, sendo $93 \%$ de seus habitantes autoclassificados pretos, negros, morenos. $\mathrm{O}$ sustento da comunidade é obtido, principalmente, por meio de plantações de subsistência. Apesar da inexistência de condições sanitárias apropriadas em Caiana dos Crioulos, como água corrente limpa para consumo humano e esgoto sanitário tratado, nenhuma doença relacionada à água nem agravos à saúde humana foram observados na população local. Dentre os problemas de saúde e agravos observados, destacam-se o consumo de álcool, a hipertensão e os problemas mentais. As pessoas têm apenas uma idéia aproximada desses problemas, mas desconhecem informações básicas a respeito de doenças e agravos prevalentes na população negra, tais como anemia falciforme e hipertensão. Palavras-chave: Remanescente de quilombo; Raça; Hipertensão; Anemia falciforme; Saneamento. 


\section{Abstract}

This work aimed to present the conditions of sanitation and human health at Caiana dos Crioulos, accredited in May 2005 by the Fundação Cultural Palmares as a remnant community of 'quilombos', to carry out a survey on the knowledge level that black people have on prevalent diseases in the African ancestry population, as well as to discuss the variable 'race' in health research. The community is formed by 522 persons, most of them are infants and adolescents, mostly of African ancestry, where $93 \%$ of them self-proclaim as black, negro, or 'moreno' (dark-complexioned person). They are supported basically by subsistence agriculture. Despite non-existent proper sanitary conditions in the village of Caiana dos Crioulos, like clean running water for human consumption and treated sewage, neither water-borne diseases nor serious injuries to human health were observed in the human population. The most noteworthy health problems and injuries observed in the population were the consumption of alcohol, hypertension, and mental disorders. Local people have just a vague idea of such problems but they ignore basic information of prevalent diseases and injuries in black population like sickle cell anemia and hypertension.

Keywords: Remnant of Quilombo; Race; Hypertension; Sickle Cell Anemia; Sanitation.

\section{Introdução}

As comunidades remanescentes de quilombos são espaços habitados secularmente por descendentes de mulheres e homens escravizados, ex-escravizados e também de negros livres. Contudo, só a partir da década de 1980, deixaram de ser vistas como comunidades pretéritas, devido a ações políticas dos movimentos sociais negros. $\mathrm{O}$ marco legal, relativo a essas comunidades, se estabeleceu na Constituição Federal de 1988, no Artigo 68, do Ato das Disposições Constitucionais Transitórias. A presença legalmente instituída levou a Fundação Cultural Palmares, em 1994, a formular um novo conceito para os quilombos, que passaram a ser vistos como: "toda comunidade negra rural que agrupe descendentes de escravos vivendo de uma cultura de subsistência e onde as manifestações culturais têm forte vínculo com o passado" (Arruti, 2002; Nery, 2004).

Todas as regiões brasileiras apresentam áreas remanescentes de quilombos, estando catalogado, por todo o país, um total de 2790 comunidades, revelando panoramas regionais bem distintos. A região Nordeste conta com 1672 registros, seguida pela região Norte, com 442. No Sudeste, no Centro-Oeste e no Sul encontram-se 375,131 e 170 registros, respectivamente (Anjos e Cipriano, 2007). A Paraíba, de acordo com as informações fornecidas pelo Instituto Nacional de Colonização e Reforma Agrária (Incra), em outubro de 2006, apresenta uma listagem com 17 comunidades ${ }^{1}$.

A comunidade de Caiana dos Crioulos, reconhecida pela Fundação Cultural Palmares como área remanescente de quilombo, em 30 de maio de 2005, localiza-se no topo da Serra da Borborema, no limite dos municípios de Alagoa Nova, Massaranduba e Alagoa Grande, à qual se encontra ligada administrativamente. Esse município dista da capital do estado, João Pessoa, cerca de $120 \mathrm{~km}$, estando a comunidade distante do município sede cerca de $12 \mathrm{~km}$, ambas interligadas por uma estrada de terra, em péssimo estado de conservação. Alagoa Grande apresenta uma população de

1 De acordo com informações obtidas no escritório do Incra-PB, com sede em João Pessoa, em agosto de 20o6, a Paraíba conta com 17 comunidades negras, dessas 12 já possuem certidões de auto-reconhecimento emitidas pela Fundação Cultural Palmares. As comunidades já reconhecidas são Vinhas, no município de Cajazeirinha; Pitombeira, na cidade de Várzea; Caiana dos Crioulos, em Alagoa Grande; Gurugi e Mituaçu, no município do Conde; Paratibe, na cidade de João Pessoa, Sítio Matias, em Serra Redonda, a comunidade negra Rural Lagoa Rasa, em Catolé do Rocha; Pedra da Água, em Ingá; Serra do Talhado, no município de Santa Luzia e as comunidades de Matão e Engenho do Bonfim, nas cidades de Gurinhém e Areia, respectivamente. 
aproximadamente 30 mil habitantes, sendo $51,3 \%$ de mulheres e $48,7 \%$ de homens. Quanto à cor, $36 \%$ se autoclassificam brancos, $57,7 \%$ pardos e $5,7 \%$ pretos, esses dois grupos perfazem um total de $63,4 \%$ de negros. Do total de residentes, $42,2 \%$ moram na zona rural (IBGE, 2001) e o restante, $57,8 \%$ na zona urbana. Os índices de pobreza econômica, de emprego formal e de escolaridade são respectivamente 0,225 ; 0,041 e o,229, caracterizando uma população com altos índices de pobreza econômica e de desemprego, bem como uma baixa escolaridade (Pochmann e Amorim, 2003).

Logo que se chega a Caiana dos Crioulos, é possível avistar o núcleo da comunidade, onde se encontram a igreja e uma mercearia. Um pouco mais afastada, está uma escola de ensino fundamental e a casa de farinha. Nos últimos anos, também foram instalados dois postos: um de venda de passagens interestaduais e, outro, de saúde. Este último funciona com limites de horário e com poucos profissionais. As residências se localizam nas proximidades dos roçados de cada família. A terra tem sido destinada ao plantio de lavoura de subsistência em pequenos lotes que, segundo moradores, diminuem a cada ano, e cuja produção torna-se insuficiente para se viver adequadamente e com um mínimo de qualidade.

Caiana dos Crioulos apresenta outros problemas que impedem a solução da falta de terra aos seus moradores, uma vez que quase não há possibilidade de expansão territorial, em razão de estar cercada por propriedades particulares e vários assentamentos rurais, terras já tituladas pelo Incra. Dessa forma, com o crescimento da população local e por não haver terras para todos, muitos homens jovens migraram em busca de alternativas econômicas para a sobrevivência e a melhoria nas condições de vida. Nesse sentido, as cidades do Rio de Janeiro e de São Paulo são as que mais atraem a população masculina. Também houve casos de mulheres e homens de Caiana dos Crioulos se inseriram em movimentos sociais, procurando conquistar lotes de terra e, assim, manter o vínculo com o meio rural. A migração para centros urbanos também foi identificada em outras comunidades negras rurais do Nordeste, a exemplo do que ocorre em Con- ceição das Crioulas, localizada no estado de Pernambuco. Nessa comunidade, os mais jovens partem em busca de trabalho em cidades como Recife e São Paulo (Souza, 2002).

A população de Caiana dos Crioulos é formada, majoritariamente, por pessoas que se reconhecem como pertencentes à "raça" negra². Possivelmente, a freqüente identificação dos moradores de Caiana dos Crioulos como negro vincula-se tanto em razão do tratamento dado pelos moradores das circunvizinhas e de Alagoa Grande que sempre os trataram como pessoas "escuras" e diferentes, quanto pela a participação em movimentos sociais negros, desde a década de 1990, de muitos moradores que contribuíram para a incorporação da positividade de ser negro.

A popularização dos meios de transportes rodoviários foi fundamental para facilitar o deslocamento dos moradores de Caiana dos Crioulos com a população de Alagoa Grande e, também, com João Pessoa e Campina Grande, favorecendo o acesso aos serviços de saúde e ao comércio. Mas será que esse contato favoreceu mudanças materiais e melhoria na condição de vida dos moradores dessa comunidade?

Nesse sentido, o objetivo deste artigo é apresentar um diagnóstico de algumas condições de saúde da comunidade remanescente do quilombo Caiana dos Crioulos, para avaliar a qualidade de vida usufruída (ou não) por mulheres e homens trabalhadores rurais que residem nessa área. Os resultados deverão contribuir para o reconhecimento dos problemas de saúde que os afligem, como são percebidos pelos moradores e subsidiar políticas públicas voltadas para essa comunidade.

\section{Considerações Metodológicas}

Os resultados aqui apresentados foram baseados em três fontes de pesquisa: no formulário produzido pelo Ministério da Saúde, denominado Sistema de Informações de Atenção Básica (SIAB); no questionário individual, estruturado com dezesseis questões e aplicado a 148 pessoas, e nas entrevistas não estruturadas, realizadas com 10 membros da comunidade, sendo cinco homens e cinco mulheres. Os dois últimos

20 termo "raça", aqui utilizado, não se refere aos aspectos biológicos de indivíduos, sendo entendido como uma categoria política ressignificada pelo movimento negro brasileiro contemporâneo. 
instrumentos de pesquisa foram elaborados e aplicados, para completar e ampliar os dados do SIAB sobre a população de Caiana dos Crioulos.

A análise se baseou nas abordagens quantitativa e qualitativa, cujos itens selecionados foram alguns dos que se referem à qualidade de vida, considerados básicos para suprir as necessidades de existência de homens e mulheres na época contemporânea, a saber: acesso aos serviços de saúde, tipo de habitação, meio ambiente, trabalho e educação. Esses indicadores sociais permitem perceber como vivem as pessoas de Caiana dos Crioulos, se as exigências e as demandas para uma vida saudável e com qualidade são satisfeitas, como propõe a visão ampla de saúde que vigora na atualidade, a qual informa que ter saúde não é apenas o não estar doente, mas o resultado das condições alimentares, da educação, do meio ambiente, do transporte, do acesso a posse da terra e ao lazer.

Com as informações obtidas no formulário do SIAB, foi possível estimar o número de famílias e de habitantes da comunidade; identificar as condições sanitárias e algumas doenças que atingem as pessoas e variados indicadores sociais (idade, escolaridade, habitação, se dispõem de energia elétrica e de serviços sanitários e outros). Com a segunda fonte, o questionário individual estruturado, aplicado na primeira semana de abril de 2006, obtiveram-se dados sobre idade, "raça"/cor, religião, e, sobretudo, em relação ao conhecimento das pessoas acerca de algumas doenças prevalentes na população negra e/ou agravos adquiridos por tratamento inadequado, por falta de acesso aos serviços públicos de saúde. Finalmente, a partir das entrevistas não estruturadas, foram coletadas informações sobre o acesso a serviços de saúde, o tipo de alimentação e o estado nutricional.

\section{Resultados}

\section{Caracterização etária, étnico-racial e socioeconô- mica da população estudada}

A comunidade é formada por 128 famílias, que totalizam, aproximadamente, 562 pessoas, um número $50 \%$ menor que o estimado em 1995 por Aquino (2001). Com relação aos dados da população estudada por sexo e faixa etária, tabulados a partir de informações do SIAB, foi possível constatar que:
- existe um equilíbrio quanto ao número de pessoas do sexo feminino $(49,81 \%)$ e do masculino $(50,19 \%)$; somente no grupo com mais de 60 anos, as mulheres foram encontradas em maior número $(7,47 \%)$, contra 4,79\% de homens;

- a população é predominantemente formada por crianças e adolescentes, de zero a 18 anos (44,45\%). A população jovem (de 19 a 23 anos) compreende (10,25\%). Considerando-se o conjunto de crianças, adolescentes e jovens, obtém-se um percentual de $54,70 \%$ de toda a comunidade negra rural. Entre os adultos (de 24 a 59 anos), estava o segundo maior grupo, somando $32,95 \%$ e, por último, as pessoas com mais de 60 anos, que compunham $12,36 \%$ do universo pesquisado;

- entre os homens, a presença de jovens (de 13 a 23 anos) constitui um significativo grupo de $13,8 \%$, contudo no grupo dos mais velhos (acima de 50 anos), esse número diminui para 7,86\%, inclusive eram encontrados em menor número que as mulheres idosas. Esse fenômeno pode ser atribuído às freqüentes migrações para o Sudeste como é também uma das causas da sua menor proporção masculina entre os adultos; já o menor número de homens idosos pode estar relacionado à menor expectativa de vida apresentada pelo sexo masculino. No ano 200o, a esperança de vida do homem e da mulher brasileira era de 64 e 72 anos de idade, respectivamente, ou seja, a população masculina vivia oito anos a menos que a feminina. Para o mesmo ano, as taxas de mortalidade para homens pardos, pretos e negros, da região Nordeste, foram superiores a das mulheres. Isso significa que a expectativa de vida feminina é maior que a masculina (Batista e col., 2005). Essa diferença poderia explicar o maior número de mulheres idosas em Caiana dos Crioulos.

Considerando a autodeclaração de "raça"/cor das pessoas residentes, obtiveram-se as seguintes informações: - as categorias pelas quais 148 pessoas de Caiana dos Crioulos se autoclassificaram negra $(39,19 \%)$, preta $(2,70 \%)$, morena (19,59\%), mulata $(14,86 \%)$, parda $(17,57 \%)$ somam, portanto, uma população de 94,08\% das mulheres e dos homens entrevistados, indicando o reconhecimento da ancestralidade africana. Apenas $5,26 \%$ se reconheceram brancas, e menos de $1 \%$, com ascendência indígena; 
- um aspecto que merece ser destacado é como a categoria negra foi intensamente utilizada por mulheres e homens da comunidade em estudo. Mesmo que esse termo não conste das categorias usadas pelo IBGE, provavelmente, o trabalho de re-significação feito pelo movimento negro paraibano tem tido resultado. 0 termo é utilizado não só para demarcar uma identidade étnico-racial, como também para uma identificação política, o que sugere a existência de uma identidade étnico-racial contemporânea de base cultural e política em Caiana dos Crioulos. Assim, autodenominaram-se negros $21,05 \%$ das mulheres e $17,11 \%$ dos homens da comunidade. Essa identidade se mostra vinculada a uma afirmação do ser negro ou negra, em oposição à ideologia da mestiçagem e da democracia racial, que apagariam as diferenças. Nesse sentido, observa-se a "reidentificação" dos afro-ascendentes, apesar da referência discursiva à "raça", como substituto das pertenças étnicas obliteradas pela escravidão (Costa, 2002), e ao estigma culturalmente construído a respeito de homens e mulheres negras. Assim: $2,70 \%$ e $\mathbf{1 7}, 57 \%$, das pessoas entrevistadas fizeram uso das categorias censitárias preta e parda, respectivamente, e 19,59\% se autoclassificaram com a categoria nativa morena, a qual é, continuamente, veiculada na mídia brasileira e incorporada por um grande número de pessoas no nosso país. Não chega, portanto, a ser uma surpresa o uso dessa categoria, por quase $20 \%$ das pessoas quilombolas, pois elas estão interligadas ao mundo globalizado por meio das antenas parabólicas existentes em muitas casas da região. Contradições do mundo contemporâneo? Afinal, apesar do baixo poder aquisitivo da maioria das residências dos moradores, mantém-se o contato com o mundo exterior.

A atividade produtiva de 354 pessoas, tabulada a partir dos formulários do SIAB, permitiu a elaboração do seguinte quadro:

- A maioria dos habitantes da comunidade (mulheres e homens) dedica-se à pequena agricultura (98,24\%), e uns poucos homens ( $1,46 \%)$, ao trabalho da construção civil. Entre os últimos devem estar os homens que retornaram do Sudeste e passaram a preferir assumir essa profissão do mundo urbano e/ou outros que aprenderam a profissão e realizam serviço de manutenção na própria comunidade ou mesmo no município de Alagoa Grande.
- Nos "roçados" da comunidade, desenvolve-se uma agricultura de subsistência, baseada, principalmente, no plantio de cereais (milho, feijão e fava) e de tubérculos (macaxeira, inhame e batata-doce). Cultivam-se também algumas árvores frutíferas como a mangueira, o cajueiro, a bananeira, a jaqueira e a laranjeira e criam-se animais domésticos. As frutas, além de fazerem parte da dieta de mulheres e homens da comunidade em análise, constituem importante complemento da renda, visto que, pelo menos, um dia da semana, normalmente os sábados, muitos moradores se dirigem ao centro de Alagoa Grande para comercializar tais produtos, que fazem parte da cultura alimentar da população da Paraíba.

\section{Escolarização e freqüência à escola}

Apesar dos dados do SIAB fornecerem apenas informações sobre a matrícula das crianças e dos jovens na escola e não divulgar a série freqüentada por eles, foi possível analisar o número de pessoas matriculadas na escola local, nas faixas etárias de o a 18 anos. Mesmo com essa limitação, os resultados revelam um quadro altamente preocupante, pois:

- do total de 232 crianças e jovens, de ambos os sexos, apenas 80 (34,48\%) freqüentam a escola. As demais, 152 (65,52\%), estão ou estavam fora de sala de aula;

- são dois os aspectos em comum entre meninas e meninos: primeiro se identificou a ausência de ambos no ensino pré-escolar de um total de 65 crianças (35 meninas e 20 meninos), apenas quatro, com até seis anos, freqüentavam a escola, segundo: os jovens, de ambos os sexos, na faixa etária entre 15 e 18 anos, estão totalmente ausentes da escola, nesse período, geralmente, cursa-se o ensino médio. No caso de Caiana dos Crioulos, todos eles, 31 garotas e 49 garotos constam na ficha do SIAB, não como estudantes, mas, como agricultores;

- na faixa etária de 7 a 10 anos, período em que, geralmente, cursa-se a primeira fase do ensino fundamental ( $1^{\mathrm{a}}$ a $4^{\mathrm{a}}$ séries), as meninas estavam em grande desvantagem, visto que, de um total de 20, apenas 6 (ou $5,36 \%$ do total de meninas) estavam matriculadas, enquanto entre os meninos, de 32 , havia 20 (ou $16,67 \%$ do total) freqüentando a sala de aula.

Considerando que nas fichas do SIAB não constam as séries nas quais as crianças e os jovens estão/estavam matriculadas, não foi possível obter dados sobre 
a evasão ou defasagem entre série e idade das crianças da comunidade. Mas, de qualquer maneira, o quadro evidenciado é de manutenção da pobreza e comprometimento das futuras gerações.

\section{Caracterização dos domicílios e condições sanitárias}

Na comunidade estudada, os vários domicílios apresentam-se isolados e dispostos de uma forma que praticamente não formam arruamentos. Embora existam Caiana de Baixo e Caiana de Cima, é em Caiana dos Crioulos onde se encontra o núcleo formado majoritariamente por pessoas negras. A expressão "dos Crioulos" revela o pertencimento racial, configurando uma identidade vinculada a uma matriz africana. A ausência de ruas também caracteriza as comunidades de Alcântara, Ivaporunduva e Kalunga, mas estas diferem de Caiana dos Crioulos por serem formadas por 24, 8 e 62 povoados diferentes (Brasil, 2005).

Muitas das casas foram edificadas em taipa, ou seja, com estrutura de madeira, e enxertadas com barro. Atualmente, é possível observar, na paisagem de Caiana, algumas residências de alvenaria. De acordo com as informações obtidas através do SIAB, as 128 famílias residem em domicílios que apresentam em média cinco cômodos, o que representa 37,4\% das casas; o número de cômodos se mostra superior ao detectado nas comunidades quilombolas de Alcântara, com dois cômodos, e de Ivaporunduva e Kalunga, com um (Brasil, 2005). Porém esses domicílios apresentam poucos itens que os transformem em locais confortáveis e que ofereçam qualidade de vida, aqui entendida, de acordo com Souza e Kalichman (1994), como "condição de existência dos homens sempre referida ao modo de viver em sociedade, isto é, dentro dos limites que são colocados em cada momento histórico para se viver o cotidiano". Um dos poucos itens se refere à existência, desde 1993, de serviço de eletrificação. Em 99,9\% das casas existentes na comunidade, apenas duas residências (1,1\%) não estão abastecidas com esse tipo de serviço.

O abastecimento de água é um problema gravíssimo, sendo motivo de grande preocupação entre os moradores, pois nenhum dos 128 domicílios conta com água encanada. Quase a metade das casas de Caiana (46,09\%) é suprida por água proveniente de barragem, seguido da água retirada de poços (14,06\%); cisternas $(16,41 \%)$, cacimbas $(8,59 \%)$ e poços/nascentes $(8,59 \%)$.
Apenas 6,26\% não informaram a fonte de obtenção da água para o consumo doméstico. Nas comunidades de Alcântara e Kalunga, o percentual de residências que não são abastecidas por água canalizada é de 70\% e $77 \%$, respectivamente (Brasil, 2005), o que demonstra que o abastecimento de água é um problema também para outras áreas remanescentes de quilombos.

Em relação à forma de tratamento da água destinada ao consumo humano, a população de Caiana faz uso da cloração $(82,81 \%)$ e da filtração $(1,56 \%)$. 0 restante dos domicílios, quase $15 \%$, não realiza qualquer tipo de tratamento da água de consumo.

Quanto ao destino dos dejetos, 82,03\% dos domicílios contam com fossa seca, e o restante das pessoas investigadas, $17,97 \%$, não especificou como descartam as excretas humanas. A maior parte dos moradores da comunidade em estudo não dispõe de banheiro no interior ou mesmo nas proximidades de suas residências. Esse é outro sério problema dessa população, pois o uso do meio ambiente para descartar as fezes favorece a proliferação de vetores e de microorganismos causadores de doenças endêmicas e de parasitoses, como também a contaminação da água dos mananciais de superfície, prejudicando, ainda mais, a qualidade da água consumida pelas pessoas.

A comunidade também não dispõe de depósito nem de serviço de coleta de resíduos sólidos domiciliares, sendo comum o descarte do lixo em lugares inadequados, como o que vem ocorrendo: a maioria dos moradores, ou quase $86 \%$ deixa-o abandonado em terrenos localizados nas proximidades das casas, mas pouco freqüentados por eles; dos que queimam e/ou enterram estavam quase $8 \%$, e 6,25\% não responderam qual o destino dado aos detritos que produzem. Situação semelhante ocorre em outras comunidades, como a de Alcântara (MA), na qual 55\% deixam o lixo acumulado em terrenos, e somente $37 \%$ têm por hábito queimálo (Brasil, 2005). A ausência de procedimentos sanitários adequados aos resíduos domésticos produzidos nas comunidades remanescentes tem sido ponto de discussão nos Encontros Nacionais das Comunidades Remanescentes de Quilombos, a exemplo da que ocorreu em 2001, quando um dos pontos de reivindicação foi a "Capacitação de agentes ambientais e preservação do meio ambiente (lixo, queimada, poluição dos rios)" (Brasil, 2002, a).

Dados do Fundo das Nações Unidas para a Infân- 
cia (Unicef, 1995) informavam que 9o\% das famílias rurais do Nordeste do Brasil não contam com água no interior de suas residências; que 29,5\% das famílias (rurais e urbanas) da Paraíba não dispunham de nenhum tipo de banheiro em seus domicílios e, considerando a população rural, mais de 70\% das famílias rurais encontravam-se na mesma situação, ou seja, não tinham um local adequado para destinar os dejetos. A ausência de água e de banheiro no interior das residências foi observada em $100 \%$ das residências de Caiana dos Crioulos. Mudanças na situação sanitária dessa comunidade foram sinalizadas em novembro de 2004, com a proposta de política pública da Fundação Nacional de Saúde (Funasa), que assinou um termo de cooperação técnica com a Fundação Cultural Palmares, com o intuito de promover obras de saneamento básico nas comunidades quilombolas (Nery, 2004), no entanto, passados mais de dois anos, o perfil sanitário dessa comunidade permanece inalterado.

O Artigo 21, inciso XX, da Constituição brasileira de 1988 tornou de competência da União as diretrizes para o desenvolvimento urbano, incluindo aí a habitação e o saneamento básico. Já o Artigo 200, incisos IV e VIII, determina como uma das competências do Sistema Único de Saúde (SUS) a formulação da política de saneamento básico e a proteção ao meio ambiente e, para nortear ainda mais as ações do SUS, o Artigo 198 , por meio do inciso II, coloca o "atendimento integral, com prioridade para as atividades preventivas, sem prejuízo dos serviços assistenciais" (Brasil, 1988). Um dos princípios do SUS é o da eqüidade, o qual garantiria a mesma atenção à saúde para a mesma necessidade. 0 direito garantido pela Constituição e o princípio da eqüidade não têm sido suficientes para assegurar a essa comunidade quilombola uma política pública eficaz no sentido de, por meio de obras de infra-estrutura, melhorar sua qualidade de vida e inclusão social. 0 princípio da eqüidade foi concebido sob a perspectiva da ética e da justiça, que auxiliam na construção da cidadania e dos direitos. Esse conjunto, quando confrontado com a desigualdade, a miséria e uma inclusão social adversa, revela o caminho possível da luta política e da busca de direitos democraticamente conquistados, o que, certamente, implica no fortalecimento da sociedade civil e de suas formas plurais de organização, permitindo a emergência de novas identidades e de novas representações, o que pode ser observado em Caiana, por meio das inúmeras reivindicações encaminhadas por meio da associação de moradores, bem como pelo significativo número de pessoas que se autoclassificaram negras.

Várias pesquisas demonstram a associação entre a ausência de infra-estrutura básica com os agravos à saúde (Costa e col., 2005) relacionados à falta de saneamento, de esgoto e de água tratada e do acúmulo de resíduos sólidos (Heller, 1998; Teixeira e Heller, 2005), geradores de eventos mórbidos tais como diarréia e parasitoses intestinais, principalmente, em crianças.

Em relação à diarréia, tem-se detectado uma grande vulnerabilidade biológica de crianças com a idade inferior a dois anos, algo que é observado nas regiões Sul, Sudeste e Nordeste para habitantes de áreas rurais e urbanas, observando-se uma correlação positiva entre a diminuição do agravo com a presença de rádio e ou de televisão nos domicílios (Vásquez e col., 1999). Em Caiana dos Crioulos, apenas 3,83\%, num total de 20 crianças, estariam dentro da faixa etária de maior vulnerabilidade à doença, um percentual relativamente baixo, e a ausência de registros relativos à diarréia poderia ser explicada pelo acesso a informações obtidas por meio de rádio, de televisão, veículos de comunicação presentes em 92,2\% dos domicílios ou mesmo pelo uso da medicina tradicional. A comunidade de Ivaporunduva, localizada no município de Eldorado, no estado de São Paulo, apresenta idênticas condições sanitárias, mas a população também não cita a diarréia como um dos problemas de saúde das crianças (Brasil, 2005).

\section{Caracterização geral das condições de saúde de Caiana dos Crioulos}

0 direito à saúde foi explicitado no texto que constituiu a Organização Mundial de Saúde (OMS), em 22 de julho de 1946, o qual foi subscrito por 61 países, dentre eles, o Brasil. Pela primeira vez, a saúde passou a ser vista com "um estado de completo bem-estar físico, mental e social e não somente a ausência de afecções ou enfermidades" e ainda "a fruição do nível máximo de saúde que se possa adquirir é um dos direitos fundamentais de todo o ser humano sem distinção de 'raça', religião, ideologia política e condição econômica e social” (Meyer, 1998). Assim, saúde passa a ser entendida, não só como a ausência de doença, mas também como o bem-estar do indivíduo, o direito 
a uma alimentação saudável, a obtenção de informações seguras sobre corpo e o direito de segui-las, bem como de ter acesso a um serviço público de saúde que respeite as particularidades de cada corpo e pratique uma medicina, preocupada com a pessoa como um todo, corpo e mente, uma medicina que inclua fatores como sexo, gênero, "raça"/cor e classe social, esta última representando não somente o poder aquisitivo, mas o meio ambiente social no que se refere, por exemplo, a condições de trabalho, moradia, nível instrucional e bem estar-psicológico (Lillie-Blanton, LaVeist, 1996).

Levando-se em conta os diferentes fatores que entrariam na composição da saúde, observa-se que a população de Caiana dos Crioulos apresenta, como mencionado, uma baixa qualidade de vida e uma acentuada vulnerabilidade em razão das péssimas condições higiênico-sanitárias, evidenciadas pela ausência de serviços básicos (saneamento, água tratada) e pelo acúmulo de lixo domiciliar. Os dados, com base no SIAB, acerca das doenças que atingem crianças, jovens, adultos e idosos da comunidade em estudo, mostram que na comunidade o,39\% das mulheres e 4,23\% dos homens são alcoolistas. Já a hipertensão atinge 5,84\% das mulheres e 3,46\% dos homens.

Como pode ser observado não são descritas doenças como verminoses, diarréias e outras que ocorrem devido a ausências de condições sanitárias adequadas. Para enfrentar a deficiência dos serviços básicos e de saúde oferecidos pelo Estado a essa comunidade, as mulheres da região têm feito intenso uso do conhecimento ancestral, como a manipulação das plantas na produção de medicamentos. Essas mulheres, as rezadeiras (ou benzedeiras) e as parteiras, têm cuidado da saúde das pessoas da povoação. Ainda nos dias atuais, elas costumam fazer uso de plantas medicinais (como jatobá, cajueiro roxo, mulungu, aroeira, urtiga e muitas outras) para tratar diferentes doenças que atingem os seus filhos, esposos ou vizinhos. Essas plantas são encontradas na própria comunidade, e essa sabedoria tem sido passada de geração a geração. Foi por intermédio de algumas dessas mulheres, ligadas à Pastoral da Criança, que a comunidade passou a fazer uso da multimistura, na tentativa de diminuir a desnutrição, principalmente a infantil, que também é um grave problema da comunidade. Há aproximadamente nove anos, uma organização de mulheres negras, a Bamidelê, com sede em João Pessoa, tem dado formação política às moradores da comunidade. Além disso, junto com a organização de mulheres, um grupo de moradoras oferece cursos de produção de medicamentos, valorizam a função de parteira e mediam a capacitação dessas mulheres que se dedicam a auxiliar as parturientes.

A instalação de um posto de saúde na comunidade, que vem "funcionando" com limites de horários e com poucos profissionais, é muito recente. O Hospital mais próximo está localizado no município de Alagoa Grande, portanto, os deficientes serviços de saúde devem ser melhorados para que sejam estendidos os direitos a uma plena cidadania para essa população de quilombolas.

\section{Nível de conhecimento de agravos e doenças prevalentes na população negra}

\section{Hipertensão arterial}

A tabulação dos dados do SIAB demonstra que a hipertensão arterial afeta $5,84 \%$ de mulheres e 3,46\% de homens. Os resultados relativos a esse agravo, obtidos por intermédio das entrevistas estruturadas, demonstram um amplo desconhecimento a respeito dos fatores de risco, tais como: sobrepeso, obesidade, diabetes, estratos sociais mais baixos, baixa escolaridade, histórico familiar positivo para a doença, homens com mais de 50 anos, mulheres a partir da menopausa, dieta rica em sal e pobre em sódio (Lessa, 2001), que estariam relacionados com o surgimento desse agravo. A população pesquisada cita apenas o sal como um componente de importância tanto para o surgimento quanto para o controle da doença.

O baixo nível de conhecimento a respeito dos fatores de riscos ligados à hipertensão arterial chama a atenção, pois $57,24 \%$ das mulheres e $42,76 \%$ dos homens afirmam já terem recebido algum tipo de informação a respeito dessa doença.

De acordo com as respostas coletadas pelo questionário estruturado, observa-se que o percentual de homens e mulheres com hipertensão excede o obtido por meio da análise do SIAB. A incidência de hipertensão feminina e masculina, obtida por esse instrumento de pesquisa, foi de $16,44 \%$ e $16,13 \%$, respectivamente, o que caracteriza, de forma muito nítida a sub-notificação de uma doença de alta prevalência na 
população negra. Embora houvesse informantes adolescentes e jovens, de ambos os sexos, não foi detectada a ocorrência de hipertensão nessas faixas etárias. A pressão alta foi uma das doenças citadas pelas comunidades de Ivaporunduva, de Kalunga (Brasil, 2005 e de Furnas do Dionísio, que se localiza na Serra de Maracaju, a $40 \mathrm{~km}$ de Campo Grande, a capital de Mato Grosso do Sul (Bandeira e Dantas, 2002).

A prevalência da hipertensão arterial em pessoas negras passou a ser estudada a partir de observações sobre a doença em mulheres e homens negros estadunidenses, que apresentam taxas de pressão dentre as mais elevadas do mundo (Lessa, 2001), sendo que o uso da variável "raça", nos estudos de hipertensão, baseou-se na existência de um alelo (ou grupo de alelos) que aumentariam a suscetibilidade a essa doença, os quais teriam uma prevalência em pessoas negras, quando comparadas às brancas (Klag e col., 1991). Murray (1991) associou a pigmentação da pele à hipertensão, sugerindo que genes da melanina estariam envolvidos no mecanismo fisiológico de aumento da pressão arterial e, quanto mais escura fosse a pele, maior seria a presença desses alelos. Dessa forma, a genética tem influenciado os estudos sobre a hipertensão arterial apontando que as variações na pressão sangüínea eram determinadas por um grupo de 10 a 15 genes (Cooper e col., 1999; Harrap, 2003).

0 ponto de vista racial e naturalizante da hipertensão arterial, o qual associa essa doença unicamente à "raça" desconsiderando outros fatores, como os ambientais, pode ser questionado a partir de resultados de outras pesquisas. 0 primeira encontra suporte em teorias psicossociais que passaram a relacionar o estresse e o status socioeconômico de mulheres e homens negros estadunidenses acometidos por esse agravo às suas percepções e atitudes diante das experiências de discriminação racial e/ou de gênero e respostas fisiológicas e psicológicas observadas nos indivíduos acometidos por esse agravo (Lillie-Blanton e LaVeist, 1996). Dentre essas respostas estaria o aumento da ingestão de sal, o que comprometeria a regulação da pressão arterial (Henry, 1988). A segunda demonstrou que o aumento do número de pessoas que desenvolviam a doença na Nigéria, na Jamaica e nos Estados Unidos mostrava-se diretamente ligado ao aumento de massa corporal e de consumo de sal (Cooper e col., 1999).
É de profunda importância o entendimento de que os genes não são entidades autônomas, mas partes integrantes de um sistema auto-ajustável, que se submete aos mecanismos de regulação mediando a intensidade da resposta diante de um estímulo ambiental, seja ele a luz solar ou o estresse psicossocial. Os alelos envolvidos no controle da pressão arterial estão presentes em todas as pessoas e poderiam estar super estimulados em pessoas negras, em virtude das constantes exposições a situações de discriminação racial ou desigualdade social, às quais muitas se encontram submetidas (Oparil e col., 2003).

\section{Doença falciforme}

Na comunidade, atualmente, duas crianças com, 7 e 11 anos de idade, apresentam a doença falciforme, que ainda se mostra amplamente desconhecida pela população. Como será mostrado, com base em depoimento de duas mães de crianças de Caiana dos Crioulos que têm doença falciforme. Após inúmeras consultas das mães e das crianças aos órgãos de saúde pública, tanto de Alagoa Grande como de João Pessoa, muito tempo se passou até que se obtivesse o diagnóstico da doença, as crianças estavam com seis e dez anos de idade, respectivamente, caracterizando dois exemplos de como a doença hereditária mais freqüente no Brasil (Zago, 2001) ainda é grandemente ignorada por planejadores de saúde, profissionais de saúde, além da população em geral.

Essa afirmação se faz a partir do relato de uma das mães sobre o descaso e o despreparo dos serviços médicos, pois até o leite materno chegou a ser responsabilizado pelo estado de saúde da criança: "Olha, eu passei muito tempo aqui, daqui de Caiana até Alagoa Grande diretamente e sempre a menina inchando, inchando e febre de 40 graus"; "passava a noite todinha com ela, a noite todinha mesmo, balançando ela, e ela sem querer dormir. Isso eu ia pra Alagoa Grande, chegava lá o médico passava remédio, eu dava pra menina, desinchava" e, ao retornar para casa, "de repente, voltava tudo de novo e eu voltava de novo ao hospital, e o doutor passava exame, mas nunca descobria, só dizia que era uma anemia e na época a menina tava mamando, que ele mandou até que tirasse a mama da menina". Complementa dizendo que o desmame foi orientado porque o médico "acreditava ele que era por conta da amamentação que eu estava dando pra menina, e eu acreditando que não era porque o leite não faz mal a 
criança nenhuma, então eu achava que não era. Mesmo assim, ela não comia nada, e eu achava que, mesmo se ela comer ela tava se alimentando com o leite do seio, então eu achava que era o máximo pra ela.”

Na comunidade de Caiana dos Crioulos, mais de $60 \%$ das pessoas - 22,09 \% mulheres e $16,13 \%$ dos homens - que responderam o questionário estruturado afirmaram que já tinham ouvido falar da doença falciforme, porém quase $98 \%$ desconhecem a forma de transmissão da anemia falciforme. Apenas duas mulheres $(2,33 \%)$, por sinal as mães das crianças portadoras de tal doença, sabem que a doença é hereditária. Uma delas informou que o médico "explicou como era a doença, que já vinha de família, que não tinha cura e que sem uma cura, assim, tomando remédio, um controle né? Um controle, aí ela vive nesse controle diretamente."

Vale destacar que a falta de informação constatada sobre a doença falciforme em Caiana dos Crioulos opõe-se ao observado em relação à AIDS, pois 82,26\% dos entrevistados e 70,93 \% das entrevistadas confirmaram que receberam algum tipo de informação sobre essa doença. Quanto à forma de transmissão, $64,52 \%$ dos homens e $72,09 \%$ das mulheres conhecem sua forma de transmissão.

O Programa de Anemia Falciforme do Ministério da Saúde (PAF-MS), instituído pelo governo Federal no ano de 1996, pretende, dentre os seus objetivos gerais, "promover ações educativas, visando informar a população sobre a doença; capacitar profissionais de saúde para a prevenção, diagnosticar, tratar e promover a busca ativa de pessoas afetadas”. Esses objetivos parecem estar longe de serem alcançados, porquanto deveriam, pelo menos em parte, ter colaborado positivamente no nível informacional de moradores, no se refere à doença falciforme.

A descrição do primeiro caso de anemia falciforme, na medicina contemporânea, ocorreu em 1910, e já há mais de 40 anos de estudos em relação à sua fisiopatologia. A AIDS, por sua vez, foi descrita em 1980 (Santos e col., 2002), mas por pressão dos movimentos sociais e vontade política das autoridades brasileiras, apresenta um modelo exemplar de enfrentamento da doença. Anjos (2004) concebe que o reconhecimento da AIDS ocorreu primeiro entre homossexuais do que entre população negra. Essa visibilidade foi construída devido ao acúmulo de capital político de ativistas homossexuais ligados ao movimento social. A falta de interesse político, por parte do governo brasileiro, para estudar e divulgar a anemia falciforme restringe o estudo da doença a iniciativas isoladas de instituições de pesquisa (Kikuchi, 2003).

Recentemente, alguns pesquisadores quantificaram a incidência da doença falciforme em 24 áreas remanescentes de quilombos, de diferentes estados brasileiros, observando que, em média, o alelo para a hemoglobina S (causador da doença falciforme) aparece em 3,7\% das pessoas (Pedrosa e col., 2004). Embora a comunidade Kalunga tenha sido uma das pesquisadas, a população não citou a anemia falciforme entre as diferentes doenças que a afetam (Brasil, 2005), isso pode ter ocorrido em razão do desconhecimento da existência da doença. Num trabalho de triagem neonatal, realizada no estado de Santa Catarina, Backes e col., (2005), demonstraram a ampla presença do gene para a hemoglobina $\mathrm{S}$ em recém-nascidos brancos, gerando uma evidência de que esse não é um marcador genético específico da "raça" negra. De acordo com Zago (2004 a), embora o agravo predomine ainda entre afro-descendentes, a miscigenação crescente vai tornando a doença sem um vínculo claro com a "etnia”.

Os dados aqui apresentados, em relação à anemia falciforme, em Caiana dos Crioulos, são importantes no sentido de divulgar o que seriam os dois primeiros casos diagnosticados da doença, de alta prevalência na população negra, e cujos casos não estão descritos nos formulários do SIAB.

\section{"Raça" e saúde: uma articulação possível e pro- missora}

Tem crescido o número de publicações de pesquisadores (as) brasileiros (as) que fazem a interconexão "raça"/cor com a saúde, uma articulação que conta com uma significativa produção, principalmente nos Estados Unidos (Monteiro, 2004), onde estudiosos (as) perceberam que o primeiro grande problema para a incorporação da "raça"/cor nas imagens epidemiológicas foi admitir que a identidade racial não é fixa ou imutável, o que limita sua confiabilidade e validade (Kaplan e Bennett, 2003), dificuldades, que por si sós não inviabilizam e/ou diminuem sua importância, pois o recorte étnico/racial, nos estudos referentes à saúde, mostra-se essencial, oferecendo a oportunida- 
de de reunir evidências epidemiológicas ainda escassas (Maio e col., 2005).

A população de Caiana dos Crioulos é formada majoritariamente por pessoas negras, e quando se pensa na articulação "raça"/saúde, deve-se ter em mente que a relação do racismo com os diferentes agravos se deve não à forma de classificação, mas às noções de superioridade inerentes a essa ideologia, sendo as conseqüências decorrentes do preconceito e da discriminação, mas as causas fundamentais da desigualdade em saúde (Laguardia, 2004). Para Munanga (1999), as cores branca, negra e amarela são categorias cognitivas herdadas da história da colonização e que apresentam um conteúdo mais ideológico do que biológico, sendo por meio delas construídas as identidades muitas vezes sem se dar conta de manipulações do biológico pelo sociológico. Assim, a cor deixa de ser uma categoria objetiva tornando-se uma categoria racial, pois é a "raça" que orienta as diferentes classificações, na qual os negros estão sempre em condições de desvantagens (Guimarães, 2003).

As categorias política/cultural, nativa e censitária, autodeclaradas por mulheres e homens de Caiana dos Crioulos, referem-se às pessoas de ancestralidade africana, mas não se restringem a um sentido meramente biológico, pois abrangem também as dimensões históricas, políticas e culturais (Sousa, 2005). Elementos históricos, psicossociais e econômicos podem interferir de forma positiva no surgimento de agravos, não podendo se atribuir o aparecimento das diferentes doenças unicamente a fatores biológicos. Para Laguardia (2004), os genes, um caráter biológico, são um dentre os vários fatores que contribuem para o surgimento das doenças.

A aceitação de "raça", como uma construção socialmente elaborada, é incompatível com a idéia de que marcadores genéticos possam ser utilizados para classificar de forma eugênica grupos humanos, sendo inaceitável também que a atual era genômica, que transporta dentro de si toda uma trama de biopoderes, os quais fogem totalmente a uma mera etiologia genética, conduza a uma nova molecularização da "raça", a efeito do que se pretendeu quando do descobrimento dos grupos sangüíneos no início do século XX (Santos, 1998). Os dados genômicos são importantes como suporte analítico, mas não autorizam o(a) pesquisador(a) a ignorar o contexto histórico, econômico e po- lítico-social, tampouco inferir uma causalidade apoiada em evidências que tomam a "raça" como um marcador biológico de distinções entre seres humanos, mas na saúde pública sempre serão questionáveis alegações acerca da sua plausibilidade biológica para dar legitimidade científica aos achados de estudos sobre diferenças e hierarquias raciais (Laguardia, 2005).

Portanto, a "raça", como construção social, interage com vários marcadores, dentre os quais gênero, classe, geração e sexualidade, que associados ao racismo contribuem para desigualdades de acesso aos serviços de atenção básica à saúde (La Veist, 1996). Além disso, a população negra é mais vulnerável; isso significa dizer que há aumento de possibilidade de se adquirir doenças e diminuição nas oportunidades de proteção contra as doenças. Esse quadro é mais preocupante quando se trata de negros residentes na zona rural, como os quilombolas. Enfim, "raça" continua sendo uma categoria analítica indispensável para revelar situações de discriminações e desigualdades no âmbito da saúde, visto que, ainda, recaem sobre mulheres e homens negros, uma vez que as características fenotípicas continuam sendo usadas para diferenciar e classificar as pessoas negras de forma hierárquica e negativamente, ou seja, a expressão "raça" continua agindo no imaginário e nas práticas sociais do Brasil.

\section{Considerações Finais}

Os resultados demonstram que as condições de vida da população de Caiana dos Crioulos estão bastante precárias, uma vez que os moradores não têm acesso a serviços de saúde satisfatórios, e as projeções para um futuro próximo também são alarmantes, pois as condições ambientais e sanitárias são extremamente deficientes; o sistema de ensino atende até a oitava série; o acesso atual ao sistema de saúde é insatisfatório, pois moradores não dispõem nem de uma medicina curativa de qualidade, tampouco de uma preventiva. Assim, esse diagnóstico de saúde mostra a forte vulnerabilidade dessa população, o que aponta para a urgente necessidade de realização de políticas públicas nessa comunidade, com programas que atendam não apenas ao que é relativo a doenças, mas também aos aspectos voltados para o estabelecimento de condições de moradia e de saneamento básico. 


\section{Agradecimentos}

Agradeço à comunidade de Caiana dos Crioulos pelo acolhimento e pelas informações prestadas, pois sem elas este artigo não seria escrito; e à doutoranda em História e professora da Universidade Estadual da Paraíba, Solange Pereira da Rocha, pela leitura crítica e sugestões.

\section{Referências}

ANJOS, J. C. Etnia, raça e saúde: sob uma perspectiva nominalista. In: MONTEIRO, S.; SANSONE, L. (Org.). Etnicidade na América Latina: um debate sobre raça, saúde e direitos reprodutivos. Rio de Janeiro:

Fiocruz, 2004. p. 97-119.

ANJOS, R. S. A.; CIPRIANO, A. As comunidades no território nacional. In: ANJOS, R. S. A.; CIPRIANO, A. (Org.). Quilombolas: tradições e cultura da resistência. São Paulo: Aori Comunicação, 2007. p. 176-206.

AQUINO, A. V. Quilombos e remanescentes de quilombos da Paraíba. In: MOURA, C. Os quilombos na dinâmica social do Brasil. Maceió: Edufal, 2001. p. 255-268.

ARRUTI, J. M. A. As comunidades negras rurais e suas terras: a disputa em torno de conceitos e números. Dimensões, Vitória, v. 14, p. 243-269, 2002.

BANDEIRA, M. L.; DANTAS, T. V. S. Furnas do Dionísio (MS). In: O'DWYER, E. C. Quilombos: identidade étnica e territorialidade. Rio de Janeiro: FGV, 2002. p. 213-253.

BATISTA, L. E.; VOLOCHKO, A.; FERREIRA, C. E. C. Mortalidade da população negra adulta no Brasil: saúde da população negra no Brasil. Brasília, DF: Funasa, 2005. p. 237-314.

BACKES, C. E. et al. Triagem neonatal como um problema de saúde pública. Revista Brasileira de Hematologia e Hemoterapia, São José do Rio Preto, v. 27, n. 1, p, 43-47, 2005.

BRASIL. Constituição. Brasília, DF: Ministério da Educação, 1989.
BRASIL. I Encontro Nacional de lideranças das comunidades remanescentes de quilombos titulados. Brasília, DF: Fundação Palmares: MEC, 2002.

BRASIL. Secretaria Especial de Políticas de Promoção da Igualdade Racial. Perfil das comunidades quilombolas: Alcântara, Ivaporunduva e Kalunga. Brasília, DF, 2005.

COOPER, R. S.; ROTIMI, C. N.; WARD, R. The puzzle of hypertension in African-Americans. Scientific American, New York, v. 28o, n. 2, p. 56-63, 1999. COSTA, S. A construção sociológica da raça no Brasil. Estudos Afro-Asiáticos, Rio de Janeiro, v. 24, n. 1, p. 35-61, 2002.

COSTA, S. S. et al. Indicadores epidemiológicos aplicáveis a estudos sobre a associação entre saneamento e saúde de base municipal. Engenharia Sanitária e Ambiental, Rio de Janeiro, v. 10, n. 2, p. 119-127, 2005.

GUIMARÃES, A. S. Como trabalhar com raça e sociologia. Educação e Pesquisa. São Paulo, v. 29, n. 1, p. 93-107, 2003.

HARRAP, S. B. Where are all the blood-pressure genes? Lancet, London, v. 361, p. 2149-2151, 2003.

HENRY, J. P. Stress, salt and hypertension. Social Science \& Medicine, Oxford, v. 26, p. 293-302, 1988.

HELLER, L. Relação entre saúde e saneamento na perspectiva do desenvolvimento. Ciência e Saúde Coletiva, Rio de Janeiro, v. 3, n. 2, p. 73-84, 1998.

IBGE. Censo 20oo: características da população e dos domicílios (resultados do universo). Rio de Janeiro, 2001.

KAPLAN, J. B.; BENNETT, T. Use of race and ethnicity in biomedical publication. Journal of American Medical Association, Chicago, v. 289, n. 20, p. 27092716, 2003.

KIKUCHI, B. A. Diáspora africana e anemia falciforme. In: ASHOKA EMPREENDEDORES SOCIAIS; TAKANO CIDADANIA. Racismos contemporâneos. Rio de Janeiro, 2003. p. 127-162.

KLAG, M. J. et al. The association of skin color with blood pressure in US blacks with low socioeconomic status. Journal of American Medical Association, Chicago, v. 265, n. 5. p. 599-602, 1991. 
LAGUARDIA, J. O uso da variável raça na pesquisa em saúde. Physis - Revista de Saúde Coletiva, Rio de Janeiro, v. 14, n. 2, p. 197-234, 2004.

LAGUARDIA, J. Raça, genética \& hipertensão: nova genética ou velha eugênia? História, Ciências, Saúde - Manguinhos, Rio de Janeiro, v. 12, n. 2, p. 371-393, 2005 .

LA VEIST, T. A. Why we shoul continue to study race... but do a better job: an essay on race, racism and health. Ethnicity \& Disease, Atlanta, v. 6, n. 1/2, p. 21-29, 1996.

LESSA, I. Hipertensão arterial. In: HAMANN, E. M.; TAUIL, P. L. (Org.). Manual de doenças mais importantes por razões étnicas, na população brasileira afro-descendente. Brasília, DF: Ministério da Saúde, 2001. p. 43-51.

LILLIE-BLANTON, M.; LA VEIST, T. Race/ethnicity, the social envolvment, and health. Social Science \& Medicine, Oxford, v. 43, n. 1, p. 83-91, 1996.

MAIO, M. C. et al. Cor/raça no estudo pró-saúde: resultados comparativos de dois métodos de autoclassificação no Rio de Janeiro, Brasil. Cadernos de Saúde Pública, Rio de Janeiro, v. 21, n. 1, p. 171-18o, 2005 .

MEYER, D. E. E. Educação em saúde na escola: transversalidade ou silenciamento? In: MEYER, D. E. E. (Org.). Saúde e sexualidade na escola. 2. ed. Porto Alegre: Mediação, 1998. p. 5-17.

MONTEIRO, S. Desigualdades em saúde, raça e etnicidade: questões e desafios. In: MONTEIRO, S.; SANSONE, L. (Org.). Etnicidade da América Latina: um debate sobre raça, saúde e direitos reprodutivos. Rio de Janeiro: Fiocruz, 2004. p. 45-56.

MUNANGA, K. Rediscutindo a mestiçagem no Brasil: identidade nacional versus identidade negra.

Petrópolis: Vozes, 1999.

MURRAY, R. F. Skin color and blood pressure: genetics or environment? Journal of American Medical Association, Chicago, v. 256, n. 5, p. 639-640, 1991.

NERY, T. C. S. Saneamento: ação de inclusão social. Estudos Avançados, São Paulo, v. 18, n. 5o, p. 313-321, 2004.
OPARIL, S.; ZAMAN, M. A.; CALHOUN, D. Pathogenesis of hypertension. Annals of Internal Medicine, Philadelphia, v. 139, n. 9, p. 61-76, 2003. PEDROSA, M. A. F.; FERREIRA, L. B.; OLIVEIRA, S. F. Anemia falciforme em antigos quilombos. Ciência Hoje, Rio de Janeiro, v. 36, n. 211, p. 84-85, 2004.

POCHMANN, M.; AMORIM, R. Atlas de exclusão social. São Paulo: Cortez, 2003.

SANTOS, R. V. S. Da morfologia às moléculas, de raça a população: trajetórias conceituais em antropologia física no século XX. In: MAIO, M. C.; SANTOS, R. V. Raça, ciência e sociedade. Rio de Janeiro: Fiocruz, 1998. p. 125-139.

SANTOS, N. J. S. et al. A aids no estado de São Paulo: as mudanças no perfil da epidemia e perspectiva da vigilância epidemiológica. Revista Brasileira de Epidemiologia, São Paulo, v. 5, n. 3, p. 286-310, 2002.

SOUSA, F. M. N. Linguagens escolares e reprodução do racismo. In: BRASIL. Ministério da Educação; SECAD. Educação anti-racista: caminhos abertos pela Lei Federal no 10.639/o3. Brasília, DF, 2005. p. 185-204.

SOUZA, V. R. F. P. Conceição das Crioulas, Salgueiro (PE). In: O`DWYER, E. C. (Org.). Quilombos: identidade étnica e territorialidade. Rio de Janeiro: FGV, 2002. p. 109-140.

SOUZA, M. F. M.; KALICHMAN, A. O. Vigilância à saúde epidemiológica, serviços e qualidade de vida. In: ROUQUARYOL, M. Z. Epidemiologia e saúde. 4. ed. Rio de Janeiro: MEDISI, 1993. p. 467-476.

TEIXEIRA, J. C.; HELLER, L. Fatores ambientais associados à diarréia infantil em áreas de assentamento subnormal em Juiz de Fora, Minas Gerais. Revista Brasileira de Saúde Materno Infantil, Recife, v. 5, n. 4, p. 449-455, 2005.

UNICEF. Saúde e nutrição das crianças nordestinas: pesquisas estaduais, 1987-1992. Rio de Janeiro, 1995.

VÁSQUEZ, M. L. et al. Incidência e fatores de risco de diarréia e infecções respiratórias agudas em comunidades urbanas de Pernambuco, Brasil. Cadernos de Saúde Pública, Rio de Janeiro, v. 15, n. 1, p. 163-171, 1999. 
ZAGO, M. A. Anemia falciforme e doenças

falciformes. In.: HAMANN, E. M.; TAUIL, P. L. (Org.).

Manual de doenças mais importantes por razões

étnicas, na população brasileira afro-descendente.

Brasília, DF: Ministério da Saúde, 2001. p. 13-35.

ZAGO, M. A. Pesquisa clínica no Brasil. Ciência e

Saúde Coletiva, Rio de Janeiro, v. 9, n. 2, p. 363-374,

2004 .

Recebido em: 21/12/2006

Aprovado em: 07/05/2007

124 Saúde Soc. São Paulo, v.16, n.2, p.111-124, 2007 